\title{
Proceeding
}

Supplementary Issue: Summer Conferences of Sports Science. First International Conference in Iraq on Sport for Peace, 4 April 2019. Baghdad Science Institute, Baghdad, Iraq.

\section{Environmental regulation, green product innovation and performance: Do the environmental dynamics matter in Thai Sports industry?}

\author{
SAKAPAS SAENGCHAI ${ }^{1}$, SUDARAT RODBOONSONG², KITTISAK JERMSITTIPARSERT ${ }^{3,4}$ \\ ${ }^{1}$ Faculty of Humanities and Social Science, Suan Sunandha Rajabhat University, Bangkok, Thailand \\ ${ }^{2}$ Faculty of Humanities and Social Sciences, Uttaradit Rajabhat University, Uttaradit, Thailand \\ ${ }^{3}$ Department for Management of Science and Technology Development, Ton Duc Thang University, Ho Chi \\ Minh City, Vietnam \\ ${ }^{4}$ Faculty of Social Sciences and Humanities, Ton Duc Thang University, Ho Chi Minh City, Vietnam
}

\begin{abstract}
The research analyses the relation of external pressure for environmental policies and performance of firm through innovation of green products. Therefore, it contributes to the previous literature by depicting a clear understanding of the phenomenon. The role of environmental dynamism has been used as a moderator on the relation of firm performance and innovation for green product. This relation has been analysed by keeping in consideration the uncertainty of external environment. This phenomenon can be explained with the help of contingency theory. The static theories and operations strategies may not be effective. Using a survey-based methodology the SEM-PLS is employed to analyse the data. For development of environment, innovation of green product is a key factor. It has been revealed through findings that innovation of green product determines the performance in terms of environmental management. The study clearly depicts that when the external environmental pressure is there, the innovation of green product act as a mediating variable. Precisely, the external pressure of environmental policies can positively influence the innovation of green product, which further leads to profitability and cost efficiency for the firm. It has been showing by the study that the activities of the firm must be aligned with the environmental policies. Practical and useful insights have been provided by this study for managing environment. The research has two main limitations. It has considered the external environmental pressure as a predicting variable for innovation of green product among the sports manufacturing companies of Thailand. Keywords: Green product; Regulation; Environment; Sports; Thailand.
\end{abstract}

Cite this article as:

Saengchai, S., Rodboonsong, S., \& Jermsittiparsert, K. (2019). Environmental regulation, green product innovation and performance: Do the environmental dynamics matter in Thai Sports industry? Journal of Human Sport and Exercise, 14(5proc), S2276-S2289. doi:https://doi.org/10.14198/ihse.2019.14.Proc5.44

Corresponding author. Department for Management of Science and Technology Development, Ton Duc Thang University, Ho Chi Minh City, Vietnam.

E-mail: kittisak.jermsittiparsert@tdtu.edu.vn

Supplementary Issue: Summer Conferences of Sports Science. First International Conference in Iraq on Sport for Peace, 4 April 2019. Baghdad Science Institute, Baghdad, Iraq.

JOURNAL OF HUMAN SPORT \& EXERCISE ISSN 1988-5202

(c) Faculty of Education. University of Alicante

doi:10.14198/jhse.2019.14.Proc5.44 


\section{INTRODUCTION}

The firms can improve their performance using different managerial practices and better resource allocation. In this way, competitive advantage can be gained by the firms along with generation of profits. In the domain of operations management, the strategies of quality management are implemented by companies such as TQM to improve the level of customer satisfaction. This in return adds to the performance of organization (lqbal, Huq, \& Bhutta, 2018; Dawabsheh, Hussein, \& Jermsittiparsert, 2019; Jermsittiparsert \& Sommanawat, 2019). One of the concerns, which have gained attention in recent time, is environmental management. Practitioners as well as researchers have given significance to this concept. The concept of environmental management is used as the strategy in operations (Crane, Matten, \& Spence, 2019). Firms have started incorporating environmental concerns in supply chains. It is evident in literature that firms generate opportunities for success through incorporating environmental concerns as compared with their competitors (Jermsittiparsert, Siriattakul, \& Sangperm, 2019; Jermsittiparsert, Siriattakul, \& Wattanapongphasuk, 2019; Somjai \& Jermsittiparsert, 2019). The tradition focus in the field of operations management was cost efficiency, which has not been incorporated in terms of environmental management (Schaltegger \& Wagner, 2017). Firms focus and improve their environmental management because of the external regulatory pressure for it. The focus of previous researches is on the perspective of retailers for understanding the issues of environment by considering the perception of consumers as exogenous variable for issues of environment. The consumers' perception being difficult to determine and subjective is a possible disadvantage of this approach. Practically, different factors influence the issues of environment such as labelling and packaging (Sekaran \& Bougie, 2016). Therefore, it is supported to take the supplier's perspective for analysing the environmental concerns. It is argued that it is important to be aware of the policies and regulations related to environment, which can influence the decision to incorporate the environmental issues in the firm's supply chain. The pressure of the external regulatory authorizes is crucial as it is a key driver for environmental management (Lin \& Ho, 2016; Hussain et al., 2018). It is expected that the performance of the firm cannot be directly improved through this pressure. It has been explained as below:

The success of environmental issues integration into the organization has been recognized by researchers and it cannot be determined easily. The organizations need to work on green innovations in the development of processes for business (Dangelico, 2016). Different factors determine the success or failure of the environmental management in improving the performance of the firm. These factors may include the ability of a firm to make innovation of green product and recognize the pressure from external regulatory authorities. The previous research studies have not analysed this relationship. It is crucial to analyse the influence of innovation of green product on the relation of firm performance and external pressure. This has been used as the first research question in this study. Technical efficiency may not result from strict market regulations (Kozluk \& Zipperer, 2015). The assumption of stability of external environment is not justified in every case. Environmental regulations like several variables of operations management can vary. Considering this, it is important to analyse the relation between innovation of green product (Chan, Yee, \& Lim, 2016), external regulatory pressure for environmental management and performance of firm. This relation has been analysed by keeping in consideration the uncertainty of external environment. This phenomenon can be explained with the help of contingency theory. The static theories and operations strategies may not be effective (Formentini \& Taticchi, 2016). The external uncertainty is referred as environmental dynamism and it is the percentage change in the environment of environment (Eroglu \& Hofer, 2014). This can be used as a moderating variable from the view of contingency theory. Section 2 explains this in detail. Different level of moderating influence can be created by environmental dynamism on the relation of firm performance and innovation of green products. This has been incorporated as the second research question to be addressed in this study. A 
research framework has been proposed by this study to address the above stated research questions. The research questions have been stated as below:

- To analyse the association between innovation of green product, external pressure for environmental policies and performance of firm.

- To analyse the role of environmental dynamism as a moderator in the relation of innovation for green product and performance of firm.

The research analyses the relation of external pressure for environmental policies and performance of firm through innovation of green products (Chan et al., 2016). Therefore, it contributes to the previous literature by depicting a clear understanding of the phenomenon. The role of environmental dynamism has been used as a moderator on the relation of firm performance and innovation for green product.

\section{LITERATURE REVIEW}

The important drive, which influences the firms to work on sustainable development, is the regulatory pressure. This is certain when the European Union states are included in the target markets. A good example is the REACH Directive (European Union, 2003), which can be followed by the firms to keep a control on the chemical materials involved in the manufacturing of products (Kormishkina, 2019). It is necessary to align the activities of firms with the regulations. It is not clear about the influence of this alignment on the performance of firm. It is a key concern for the firms to improve their performance. A limited research exists on analysing the relation of external environmental pressure and performance outcome. It is shown by the empirical findings that the environmental performance can improve through environmental regulations (Nguyen \& Hens, 2015). The relation of environmental performance with the profitability of the firm may not be in linear terms. It has been found by Kang, Germann, and Grewal (2016) that there is an association between financial gains and environmental performance of a firm but the effects and causes are not clear. The environmental issues are not recognized in China. Therefore, the government has started the imposition of environmental regulations, which was set by the SEPA (State of Environmental Protection Agency) during 1980s. Further, it has been redeveloped by the MEP (Ministry of Environmental Protection) (Bai, Sarkis, \& Dou, 2015). It shows the Chinese government consent to deal with the issues of environment. The WEEE (Waste Electrical and Electronic Equipment) in Chinese was published in 2009 and executed in 2011. This has increased the pressure on the firms in China and the exported products should be up to the defined regulations of the other countries. The state-of-the-art was reviewed by Bai et al. (2015) in the China's development of corporate sustainability. It has been argued in this study that the performance of a firm can be directly improved through the pressure created by external environmental policies and regulations. There is need for getting more understanding about the conversion of environmental regulations into the performance of firm. Empirical evidence was provided by Ahi and Searcy (2015) that the competitiveness and profitability of a firm can be improved through execution of green operations. Further, a clear relation exists between the compliance of firm with environmental policies and its performance, which improves competitiveness. It was claimed by Shu, Zhou, and Gao (2016) that the influence of innovation for green product is mediated through support of government. The execution of environmental strategies is affected through the external regulatory pressure. It is positively associated with the performance of firm. There is need for examining the other factors, which can affect this process. One such factor has been explored in the next section that is innovation of green product (Chan et al., 2016). The factors of environment such as consumption of energy, use of material are involved in the innovation for green product for designing. The purpose is to eliminate the influence created on the environment during the life cycle of product (Dangelico, Pujari, \& Pontrandolfo, 2017). It was considered by Dangelico (2017) that the process environmental management of a firm can be improved through green innovation. It is linked with any expected changes such as in term of social changes, 
technology, organizational, and institutional. The burden of environment is reduced. Particularly, the competitive advantage of a firm is influence through innovation of green product (Chan et al., 2016). It was shown that a positive influence is created on the performance of firm by innovation of green product empirically in the automobile sector. This aim of a business is to achieve profitability or higher market share. When value is given to the customers, this aim can be achieved. Incorporating environmental concerns into management and operations strategy can enable the firms to improve their efficiency. The cost can be reduced, and environmental performance is improved. This relation has been verified by Fahimnia, Sarkis, and Davarzani (2015) the organizations of North American empirically. It is consistent with the assertion of Schaltegger and Wagner (2017), which suggests that firms can do innovation through practices of environmental management to offset the implementation cost of such practices. Resultantly, the practices of environmental management can be led to competitive market. A potential way to relief the environmental concerns of consumers is offered by Pedersen and Andersen (2015), which claims that sustainable practices can be advanced through analysing the relation of supply chain and design process in the textile sector. A research model has been proposed in which the performance of firm and innovation of green product are linked in terms of profitability and operations. A crucial role is played by innovation of green product in influencing the behaviour of consumer and performance of firm (Chan et al., 2016). A relevant case study was presented by Clarke-Sather and Cobb (2019) to acknowledge this statement. It was supported that without the actions of consumers, industry and government, no solution can be implemented. Another issue is highlighted through this about the pressure of external regulations. The innovation of green product can be linked with the external pressure of environment in a direct way (Chan et al., 2016). The environmental policies and regulations definitely create a pressure for the development of green products through innovation. Good performance in terms of environment cannot be resulted from pressure without the innovation of green product. This improves the performance of the firm. According to contingency theory, it has been explained in the next section. In China, it was revealed in an empirical study that the responses of organization for improve innovation of green products can be promoted through pressure from customers and regulatory policies (Huang, Greenbaum, \& Bonner, 2019). In section 2.1 and 2.2, this result has been linked with the above discussion. It has been hypothesized in the study that the innovation of green product is affected by the external regulations for environment that influence the performance of firm.

$\mathrm{H} 1$ : Pressure of environmental regulation is in significant relationship with the green product innovation.

$\mathrm{H} 2$ : Pressure of environmental regulation is in significant relationship with the cost efficiency.

$\mathrm{H} 3$ : Pressure of environmental regulation is in significant relationship with the firm profitability.

$\mathrm{H} 4$ : Green product innovation is in significant relationship with the cost efficiency.

H5: Green product innovation is in significant relationship with the firm profitability.

It is difficult to deal with the environmental issues of several supply chains in the manufacturing sector including China because of the initial outsourcing activities in the manufacturing. However, there can be considerable consequences. In order to capture the contextual factors and business dynamics including the dynamism of market, a significant role is played in the performance of firm and management of environment (Baltgailis, 2019). The failure of the environmental policies to achieve the objectives is because of the lack of such factors (Luthra, Garg, \& Haleem, 2015). An external influence is exerted by the market dynamism on the firms because of different changes caused by various sources i.e. innovation technology, expectations of customers and demand of products. Extensive research has been carried out on the influence of external environment on performance and innovation (Giudice, Carayannis, \& Maggioni, 2017). The level with which the variation in preferences of customers, technological change and variation in the supply and demand characterize the external environment is referred as environmental dynamism. The percentage change of the environmental instability is referred as environmental dynamism (Eroglu \& Hofer, 2014). The existing products become obsolete when there is rapid change in the environment in terms of technology, suppliers, 
and customers. The existing processes and products can be improved because of the environmental dynamism. This can lead to the development of improved products. It was concluded by an empirical study that the competitive advantage is affected in a significant way through environmental dynamism (Li \& Liu, 2014). The changing circumstances can be captured through innovation in products and improvements in the existing processes. Therefore, it is expected that a moderating influence can be created by environmental dynamism on performance of firm and innovation of green product. The contingency theory can help in explaining the above stated assumption. There are three variables involved in the theory, which include performance variables, response, and contextual variables (Formentini \& Taticchi, 2016). The independent situation attributes influencing the organizations are referred as contextual. One such contextual variable is environmental dynamism, which is a good example of demand uncertainty in the market (Eroglu \& Hofer, 2014). When there is a positive relation of market demand with the environmental performance, the demand fluctuation directly influences the firm's performance. Therefore, the innovation of green product is improved. Its assumption of static nature of external environment is not valid. The influence of environmental dynamism as a moderator was studied on the performance of lean operations by Bai, Satir, and Sarkis (2019). The influence of environmental dynamism as a moderator was firstly analysed by the research on innovation of green product and performance of firm. The environmental dynamism has been used in this study as a contextual variable. The external regulatory pressure is another contextual variable that is exposed to change with time. Moreover, in the paradigm of contingency theory, the innovation of the green product is a response variable. This is the result of organizational actions as a response to the contextual variables such as external regulatory pressure and environmental dynamism. The independent variables in this study are the performance variables, which determine the effectiveness of the response variable with reference to the contextual variables. Cost efficiency and profitability of the firm represent these variables in the research model. The relation of innovation of green products and performance of firm is moderated by the environmental dynamism (Liao, 2016). This has been hypothesized in $\mathrm{H} 2 \mathrm{a}$ and $\mathrm{H} 2 \mathrm{~b}$. the last hypothesis of the study has been formulated as below:

H6: Environmental dynamism is in significant relationship with the cost efficiency.

$\mathrm{H} 7$ : Environmental dynamism is in significant relationship with the firm profitability.

H8: Environmental dynamism moderates the relationship between green product innovation and cost efficiency.

H9: Environmental dynamism moderates the relationship between green product innovation and firm profitability.

\section{METHODOLOGY}

The research adopted use of questionnaire survey, which was self-administrated. The results of the questionnaire survey were used to test the formulated hypothesis. It has been shown in the Appendix that a 7-point Likert scale was used for the questionnaire. The point 1 represented strongly disagree and 7 reflected strongly agree. The questionnaire survey was conducted among the respondents of Thailand. Therefore, there was need for adaptation. In order to improve the understanding for the respondents, some sentences and words were changed. Moreover, the questionnaire was translated to Thai language from original English version and it was translated back to English to check its similarity of concepts. The back-translation method was used for this purpose. The conceptual equivalence was checked by bilingual researchers of Thailand. Three academic researchers reviewed the questionnaire and made some adjustments for improvement. A pilot test was conducted across a group of researchers (post-doctoral) to ensure the understanding of indicators and practical relevancy in Thailand (Henseler, Ringle, \& Sarstedt, 2015). Some adjustments were made in the wording based on the results of pilot test. 


\section{RESULTS}

In the current research, Statistical Package for Social Sciences (SPSS) version 22.0 and Smart PLS 2.0 M3 software were two main analysis tools used to analyse data. On one hand, SPSS was a powerful tool that catered for numerous statistical tasks in the current study. These included tasks of data entry and coding, preliminary data cleaning, descriptive statistics, t-test for detecting non-response bias, internal consistency assessment for Cronbach's alpha, missing data detection and treatment, outlier's detection, multivariate assumptions measurement (linearity common method variance, homoscedasticity, normality and multicollinearity). Additionally, we have used Smart PLS $2.0 \mathrm{M} 3$ software to estimate measurement and structural models in the confirmatory factor analysis stage. Particularly, the structural model was used for hypotheses testing. Structural equation modelling (SEM) allowed researchers to assess interrelated dependence relationships simultaneously. Researchers who were using PLS path modelling for SEM purpose were obliged to justify substantially the rationale of choosing PLS (Ahmadian \& Abdolmaleki, 2018). The choice for PLS SEM in this study was made on the basis of several considerations tailoring to the specific context and needs of the current study. These considerations were pre-clarified as in the following explanation. Firstly, the ultimate research model of the current study was conceivably complex. It had a considerable large number of indicators variables and involves many paths. Ahmadian and Abdolmaleki (2018) defined a complex model as a larger model with many latent indicators, such as 50 or more items. With such complexity, PLS SEM was deemed most suitable as it was highly competent in analysing and explaining the complex relationship. Particularly, PLS was capable of handling complex models without leading to estimation problems given its limited information procedure characteristics (Shmueli, Ray, \& Chatla, 2016). Moreover, using PLS to estimate complex model afforded greater theoretical parsimony and reduced the model complexity. Secondly, PLS was also chosen to address the problem of small sample size as PLS imposed less stringent conditions on sample size and residual allotments compared to other alternatives of SEM techniques, like AMOS and LISREL which are both covariance-based SEM techniques. In particular to the 134 usable responses for the PLS-SEM in this study, PLS was able to afford higher statistical power to address the rather complex model of the current study with limited sample size (Henseler et al., 2015). The study of Henseler et al. (2015) stated that for the validation of model the goodness-of fit index is not appropriate. For instance, researchers have concluded that with stimulated data using PLS path models, for model validation the goodness-of fit index is not suitable because the valid and invalid models cannot be separated. Therefore, for the evaluating and reporting of results of PLS-SEM path as per the recommendation of Henseler et al. (2015), a two-step process has adopted by the current study. The current study has used this process for the assessment of structural (SM)and measurement model (MM). According to Hair, Sarstedt, and Hopkins (2014) the assessment of MM is consisting of discriminant validity, determination of item reliability, internal consistent reliability and convergent validity.

Table 1. Outer Loadings.

\begin{tabular}{|l|l|l|l|l|l|}
\hline & CEff & ENDY & FPR & GPI & PER\&P \\
\hline CEff1 & 0.933 & & & & \\
\hline CEff2 & 0.904 & & & & \\
\hline CEff3 & 0.892 & & & & \\
\hline CEff4 & 0.904 & & & & \\
\hline ENDY1 & & 0.881 & & & \\
\hline ENDY2 & & 0.833 & & & \\
\hline ENDY3 & & 0.904 & & & \\
\hline ENDY4 & & 0.911 & & & \\
\hline
\end{tabular}




\begin{tabular}{|l|l|l|l|l|l|}
\hline ENDY5 & & 0.864 & & \\
\hline FPR1 & & & 0.910 & & \\
\hline FPR2 & & & 0.869 & & \\
\hline FPR4 & & & 0.920 & & \\
\hline GPI1 & & & & 0.923 & \\
\hline GPI2 & & & & 0.886 & \\
\hline GPI3 & & & & 0.931 & \\
\hline GPI4 & & & & 0.907 & \\
\hline PER\&P2 & & & & & 0.895 \\
\hline PER\&P3 & & & & & 0.899 \\
\hline PER\&P4 & & & & & 0.883 \\
\hline PER\&P5 & & & & & 0.914 \\
\hline PER\&P6 & & & & & 0.884 \\
\hline PER\&P1 & & & & & \\
\hline
\end{tabular}

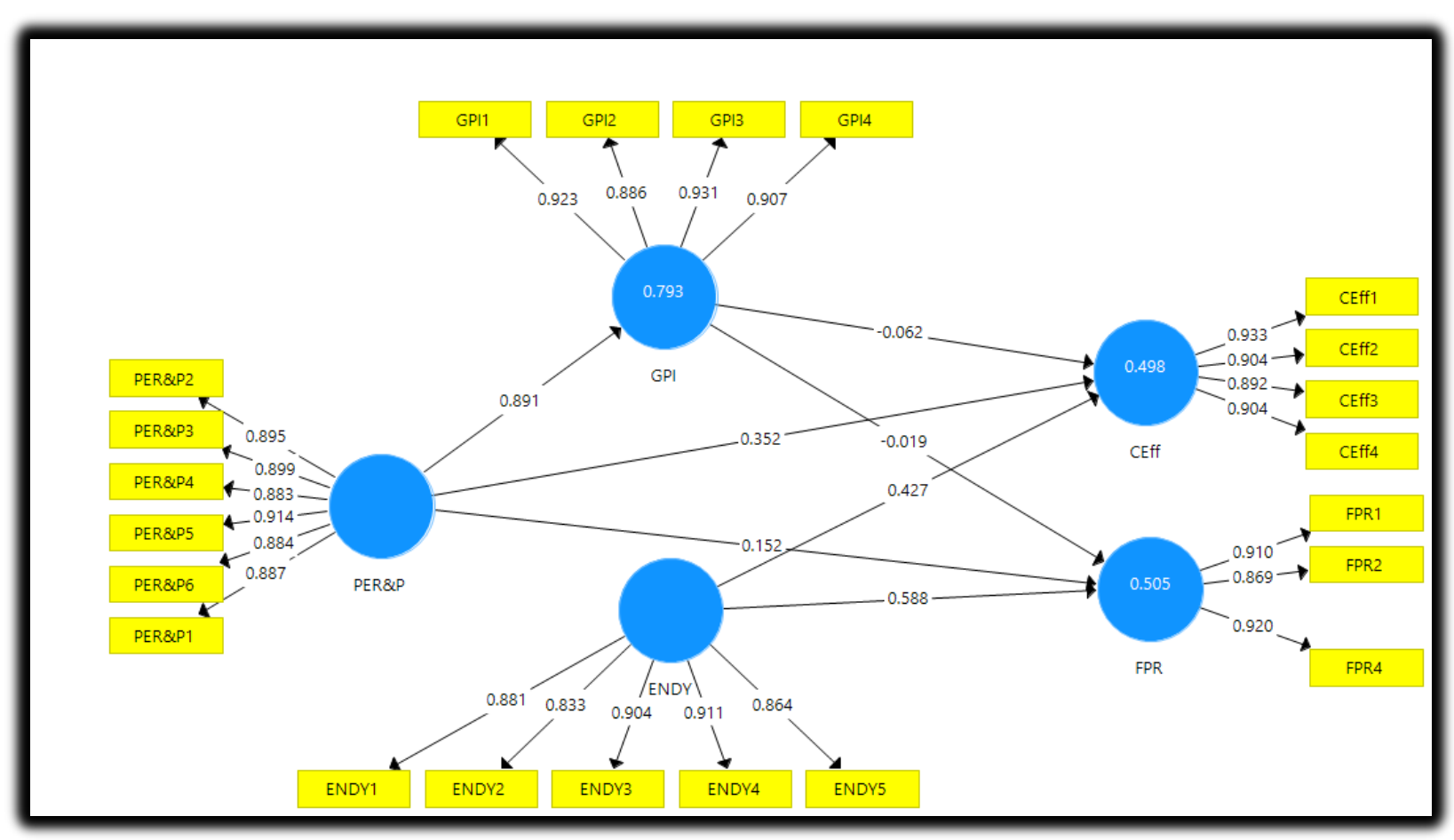

Figure 1. Measurement Model.

According to Hair et al. (2014) the reliability of each item is represented the reliability of single item. We have evaluated the reliability of individual item by analysing the outer loadings of all the constructs (Hair, Hult, Ringle, \& Sarstedt, 2016). However, the problem of weak outer loadings had frequently occurred in social science researches (Davcik \& Sharma, 2016). Item with lower loading (within the range of .40 to .70) must be deleted if the average variance extracted (AVE) and the value of composite reliability increase as per the cut off value recommended by Hair et al. (2016). The degree or level at which on specific scale the similar concept is measured by all the items. In organizational research the general estimators used for checking the instruments internal consistency reliability are the composite reliability coefficient and the Cronbach's 
alpha coefficient. However, in the current study for the determination of internal consistency reliability of adopted measures we have employed composite reliability (Hair et al., 2014).

Table 2. Reliability.

\begin{tabular}{|l|l|l|l|l|}
\hline & Cronbach's Alpha & rho_A & CR & (AVE) \\
\hline CEff & 0.929 & 0.930 & 0.950 & 0.825 \\
\hline ENDY & 0.926 & 0.930 & 0.944 & 0.773 \\
\hline FPR & 0.883 & 0.888 & 0.927 & 0.810 \\
\hline GPI & 0.933 & 0.935 & 0.952 & 0.832 \\
\hline PER\&P & 0.950 & 0.950 & 0.960 & 0.799 \\
\hline
\end{tabular}

For choosing composite reliability coefficient (CRC) rather than Cronbach's alpha there were two reasons.1) as compared to Cronbach's alpha coefficient the CRC present less biased estimate of reliability for the reason that latter on the all assumed indicators have similar loadings or in simple words similarly weighted,2) the reliability scale may overestimate or underestimate by the Cronbach's alpha. In reverse the CR considered that all indicators have dissimilar loadings. So, the contribution of all items and individual loadings are established by the composite reliability. The degree at which items signify intended latent construct, and in actual corelate with more measures of the similar latent construct is known as Convergent validity (CV). For each latent construct by the assessment of Average Variance Extracted (AVE) examined the CV as per the recommendation of Tzempelikos and Gounaris (2017).

Table 3. Discriminant Validity.

\begin{tabular}{|l|l|l|l|l|l|}
\hline & CEff & ENDY & FPR & GPI & PER\&P \\
\hline CEff & 0.908 & & & & \\
\hline ENDY & 0.892 & 0.879 & & & \\
\hline FPR & 0.811 & 0.708 & 0.900 & & \\
\hline GPI & 0.740 & 0.808 & 0.749 & 0.912 & \\
\hline PER\&P & 0.786 & 0.810 & 0.769 & 0.891 & 0.894 \\
\hline
\end{tabular}

According to Hair et al. (2014) the degree at which a specific latent construct from the other latent construct is distinctive empirically is known as discriminant validity (DV). For the examination of DV the current study has used loadings criterion and AVE criterion of Tzempelikos and Gounaris (2017). If the square root of all the latent variable is less than the square root of AVE then it establishes the DV, average variances extracted square root are shown in Table 3.

By following the recommendations of Hair et al. (2014), the present study applies the bootstrapping procedure in PLS with bootstrap of 5000 samples to treat 134 cases for the purpose of measuring the significance of the path coefficient. The application of bootstrapping in PLS was necessary according to Hair et al. (2014) because PLS SEM did not assumed the data being analysed were normally distributed. Also, the bootstrapping technique was able to produce more reasonable standard error estimates. According to Hair et al. (2014) explanation, path coefficient gave the reflection of the strength of association among the dependent and independent variables and other hypothesized relationship. 


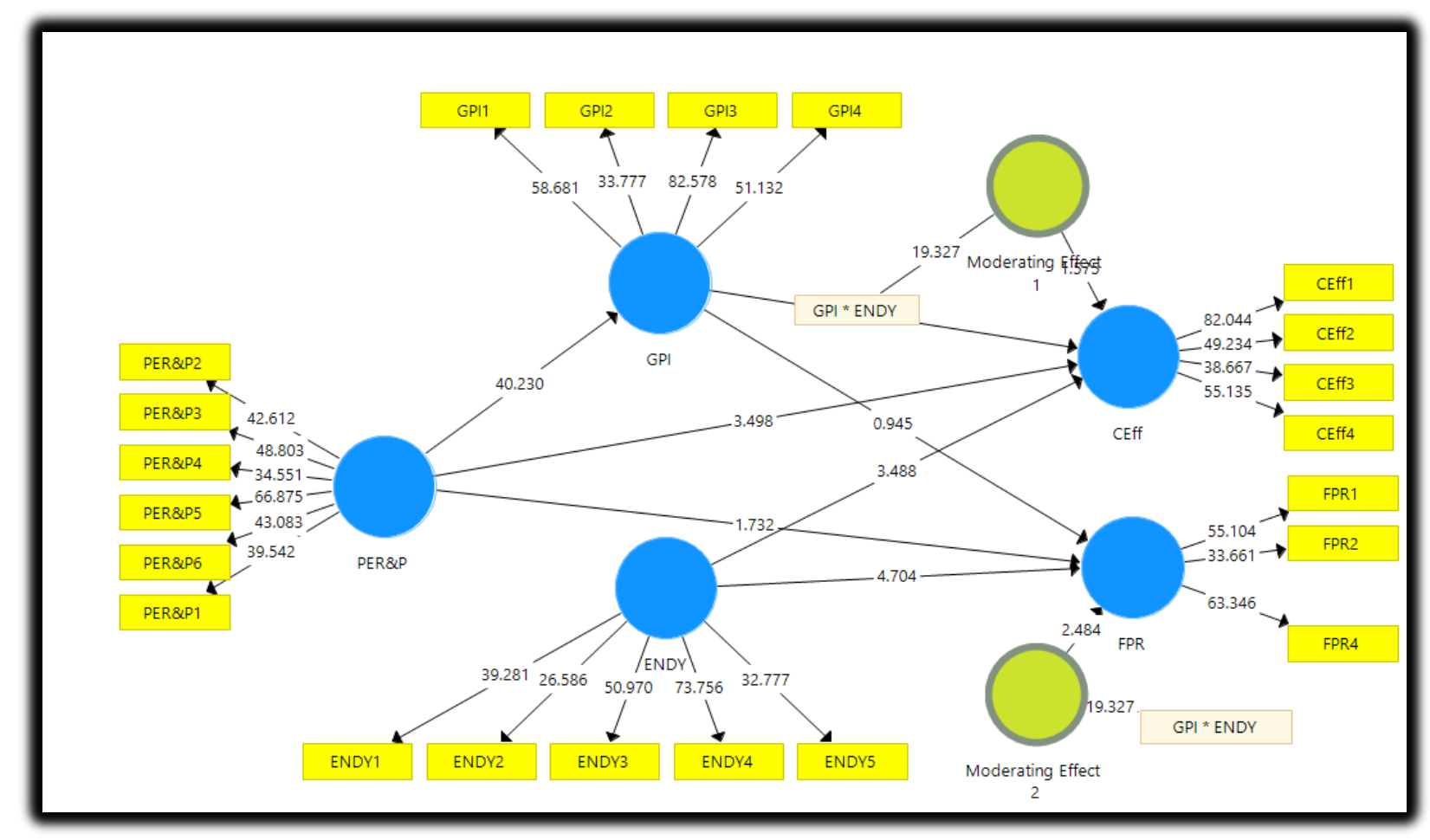

Figure 2. Structural Model.

Table 4. Structural relationship.

\begin{tabular}{|l|l|l|l|l|l|}
\hline & $(\mathbf{O})$ & $(\mathbf{M})$ & $(\mathbf{S T D E V})$ & $(\mid \mathbf{O} / \mathbf{S T D E V})$ & P Values \\
\hline ENDY -> CEff & 0.535 & 0.536 & 0.153 & 3.488 & $\mathbf{0 . 0 0 0}$ \\
\hline ENDY -> FPR & 0.750 & 0.749 & 0.159 & 4.704 & $\mathbf{0 . 0 0 0}$ \\
\hline GPI -> CEff & -0.133 & -0.128 & 0.112 & 2.196 & $\mathbf{0 . 0 0 0}$ \\
\hline GPI -> FPR & -0.127 & -0.114 & 0.135 & 0.945 & $\mathbf{0 . 1 7 2}$ \\
\hline Moderating Effect 1 -> CEff & 0.106 & 0.105 & 0.067 & 1.575 & $\mathbf{0 . 0 5 8}$ \\
\hline Moderating Effect 2 -> FPR & 0.159 & 0.158 & 0.064 & 2.484 & $\mathbf{0 . 0 0 7}$ \\
\hline PER\&P -> CEff & 0.394 & 0.389 & 0.113 & 3.498 & $\mathbf{0 . 0 0 0}$ \\
\hline PER\&P -> FPR & 0.214 & 0.202 & 0.124 & 1.732 & $\mathbf{0 . 0 4 2}$ \\
\hline PER\&P $>$ GPI & 0.891 & 0.891 & 0.022 & 40.230 & $\mathbf{0 . 0 0 0}$ \\
\hline
\end{tabular}

Empirical evidence was provided for the main effects in our study including $\mathrm{H} 1, \mathrm{H} 2 \mathrm{a}$ and $\mathrm{H} 2 \mathrm{~b}$. The results were in line with the proposition of Schaltegger and Wagner (2017) suggesting that green innovations can be developed by the firms in relation to the external pressure for environmental management. Moreover, the advantages of innovation offset the implementation cost of managing environmental issues. Firms become competitive i.e. $\mathrm{H} 1, \mathrm{H} 2 \mathrm{a}$, and $\mathrm{H} 2$. The two measurement of performance of a firm were distinguished in this research, which include profitability and cost efficiency. These reflect different organizational focuses. In explanation, some firms focus on cost (cost-oriented) and some emphasize on charging premium-pricing strategy. It has been suggested by this research that cost efficiency can be achieved through innovation of green product along with the profitability. Therefore, competitiveness can be achieved through innovation of green product and orientation. For development of environment, innovation of green product is a key factor. It has been revealed through findings that innovation of green product determines the performance in terms 
of environmental management (Fahimnia et al., 2015). The study clearly depicts that when the external environmental pressure is there, the innovation of green product act as a mediating variable. Precisely, the external pressure of environmental policies can positively influence the innovation of green product, which further leads to profitability and cost efficiency for the firm. It has been shown by the study that the activities of the firm must be aligned with the environmental policies. The ability of a firm to innovate green products and business performance of a firm is improved. The contributions have been made to literature by testing the role of innovation of green product as a mediator on the relation of operational performance and environmental regulations. The environmental policies and regulations are controlled by the government. Such policies and regulations exert pressure on the firms to comply with the environmental standards. Further, the role of innovation of green product act as a mediator in the relation of firm performance and external pressure reflects that ability of industry to innovate green products must be considered. It is easier to reduce the emissions of carbon by setting a limit. However, it is another issue whether the technical efficiency is achieved by the response of industry to this regulation. Bad outputs are not involved in the traditional method of efficiency calculation. When the equation involves these bad outputs, it reduces the overall efficiency and resources are required to maintain the good outputs level. There is need for increasing the inputs that reduce the efficiency. It is the possible cause for the role of innovation of green product as a mediator. At lower level, the decrease in the efficiency can be managed and controlled. It has been demonstrated by the results of this study that environmental regulations should incorporate practical implications. Alternatively, the burden will be shifted to the manufacturers and companies will not be able to innovate and survive. The entire economic structure is likely to be influenced in the long run. It has been implied by the findings for the influence of environmental policies on the innovation of green product that there is need to understand the issues of environment. Practically, the firms need to align their activities with the environmental policies and standards along with innovation of green products. Moreover, when the environment is dynamic (technological changes, consumer, supplier and production changes), these changes can improve the ability of a firm to achieve greater efficiency in terms of cost and profitability. Therefore, manufacturing companies must consider such changes as the environmental dynamism can affect as a moderator on the relation of cost efficiency/profitability with the innovation of green product. In PLS-SEM for the assessment of SM the other key criterion is the value of coefficient of determination $\mathrm{R}$ square (Hair et al., 2014; Henseler et al., 2015). The percentage change in DV which can be explained with one or more predicted variables is represented by the value of $R$ square (Hair, Hult, Ringle, \& Thiele, 2017). There will be a high degree of accuracy by the high value of value of $R^{2}$ (Hair et al., 2014). The minimum accepted value for the $R$ square is 0.10 as per the study. Whereas according to Hair et al. (2017) the value of $R$ square will be weak if it is 0.19 ad moderate if it is 0.33 and it is significant if it is 0.67 .

Table 5. R-square.

\begin{tabular}{|l|l|}
\hline & R Square \\
\hline CEff & 0.498 \\
\hline FPR & 0.505 \\
\hline GPI & 0.793 \\
\hline
\end{tabular}

\section{CONCLUSION}

The purpose of this research was to determine the relation between innovation of green product, environmental regulation, and performance of firm. The second objective was to determine the role of environmental dynamism as a moderator on the relation of firm performance and innovation of green product. Considering these objectives, the study developed a research model to examine the association between innovation of green product, environmental regulations, cost efficiency, and performance of a firm. A sample 
of 250 companies was used to test the model in Thailand using the SEM approach. It was revealed by the findings that there is a positive influence of external environmental pressure on the innovation of green product. It further leads to profitability and cost efficiency. The outcome of research reflects that there is strong influence of environmental dynamism as a moderator on the relation of cost efficiency and innovation of green product. However, it marginally influences the relation of profitability and innovation of green product of a firm. Practical and useful insights have been provided by this study for managing environment. The research has two main limitations. It has considered the external environmental pressure as a predicting variable for innovation of green product among the manufacturing companies of Thailand. Some other variables can be incorporated in this study, which can influence the innovation of green product. Some other predictors can influence innovation of green product. Innovation of green product can be influenced through institutional pressure (Chan et al., 2016). The future researches can identify such variables and incorporate them in analysing the influence of external pressure on green innovation. Moreover, the study has used environmental dynamism as a moderating variable. The future researches may identify some other moderating variables such as championship of management in environmental management. Based on the institutional theory, future studies can explore the way in which companies are motivated to implement a proactive strategy for environmental management. Moreover, it can be investigated about the way in which organizational value including culture and learning moderate the relationship.

\section{REFERENCES}

Ahi, P., \& Searcy, C. (2015). An analysis of metrics used to measure performance in green and sustainable supply chains. Journal of Cleaner Production, 86, 360-377. https://doi.org/10.1016/j.jclepro.2014.08.005

Ahmadian, S., \& Abdolmaleki, S. (2018). Network typology and international opportunity recognition: moderating role of entrepreneurial orientation. Journal of Global Entrepreneurship Research, 8(1), 17. https://doi.org/10.1186/s40497-018-0104-8

Bai, C., Sarkis, J., \& Dou, Y. (2015). Corporate sustainability development in China: review and analysis. Industrial Management \& Data Systems, 115(1), 5-40. https://doi.org/10.1108/imds-09-2014-0258

Bai, C., Satir, A., \& Sarkis, J. (2019). Investing in lean manufacturing practices: an environmental and operational perspective. International Journal of Production Research, 57(4), 1037-1051. https://doi.org/10.1080/00207543.2018.1498986

Baltgailis, J. 2019. The issues of increasing the effectiveness of teaching comparative economics, Insights into Regional Development 1(3): 190-199. https://doi.org/10.9770/ird.2019.1.3(1)

Chan, H. K., Yee, R. W., \& Lim, M. K. (2016). The moderating effect of environmental dynamism on green product innovation and performance. International Journal of Production Economics, 181, 384391. https://doi.org/10.1016/j.ijpe.2015.12.006

Clarke-Sather, A., \& Cobb, K. (2019). Onshoring fashion: Worker sustainability impacts of global and local apparel production. Journal of Cleaner Production, 208, 1206-1218. https://doi.org/10.1016/j.jclepro.2018.09.073

Crane, A., Matten, D., \& Spence, L. (2019). Corporate social responsibility: Readings and cases in a global context: Routledge. https://doi.org/10.4324/9780429294273-2

Dangelico, R. M. (2016). Green product innovation: where we are and where we are going. Business Strategy and the Environment, 25(8), 560-576. https://doi.org/10.1002/bse.1886

Dangelico, R. M. (2017). What drives green product development and how do different antecedents affect market performance? A survey of Italian companies with eco-labels. Business Strategy and the Environment, 26(8), 1144-1161. https://doi.org/10.1002/bse.1975 
Dangelico, R. M., Pujari, D., \& Pontrandolfo, P. (2017). Green product innovation in manufacturing firms: A sustainability-oriented dynamic capability perspective. Business Strategy and the Environment, 26(4), 490-506. https://doi.org/10.1002/bse.1932

Davcik, N. S., \& Sharma, P. (2016). Marketing resources, performance, and competitive advantage: A review and future research directions. Journal of Business Research, 69(12), 5547-5552. https://doi.org/10.1016/j.jbusres.2016.04.169

Dawabsheh, M., Hussein, A., \& Jermsittiparsert, K. (2019). The Triangular Relationship between TQM, Organizational Excellence and Organizational Performance: A Case of Arab American University Palestine. Management Science Letters, 9(6), 921-932. https://doi.org/10.5267/j.msl.2019.2.010

Eroglu, C., \& Hofer, C. (2014). The effect of environmental dynamism on returns to inventory leanness. Journal of Operations Management, 32(6), 347-356. https://doi.org/10.1016/j.jom.2014.06.006

Fahimnia, B., Sarkis, J., \& Davarzani, H. (2015). Green supply chain management: A review and bibliometric analysis. International Journal of Production Economics, 162, 101-114. https://doi.org/10.1016/.i.ipe.2015.01.003

Formentini, M., \& Taticchi, P. (2016). Corporate sustainability approaches and governance mechanisms in sustainable supply chain management. Journal of Cleaner Production, 112, 1920-1933. https://doi.org/10.1016/j.jclepro.2014.12.072

Giudice, M., Carayannis, E. G., \& Maggioni, V. (2017). Global knowledge intensive enterprises and international technology transfer: emerging perspectives from a quadruple helix environment. The Journal of Technology Transfer, 42(2), 229-235. https://doi.org/10.1007/s10961-016-9496-1

Hair, Hult, G. T. M., Ringle, C., \& Sarstedt, M. (2016). A primer on partial least squares structural equation modeling (PLS-SEM): Sage publications. https://doi.org/10.3926/oss.37

Hair, Hult, G. T. M., Ringle, C. M., \& Thiele, K. O. (2017). Mirror, mirror on the wall: a comparative evaluation of composite-based structural equation modeling methods. Journal of the Academy of Marketing Science, 45(5), 616-632. https://doi.org/10.1007/s11747-017-0517-x

Hair, Sarstedt, M., \& Hopkins, L., Kuppelwieser, Volker. (2014). Partial least squares structural equation modeling (PLS-SEM) An emerging tool in business research. European Business Review, 26(2), 106-121. https://doi.org/10.1108/ebr-10-2013-0128

Henseler, J., Ringle, C. M., \& Sarstedt, M. (2015). A new criterion for assessing discriminant validity in variance-based structural equation modeling. Journal of the Academy of Marketing Science, 43(1), 115-135. https://doi.org/10.1007/s11747-014-0403-8

Huang, Y.-S. S., Greenbaum, R. L., \& Bonner, J. M. (2019). Why sabotage customers who mistreat you? Activated hostility and subsequent devaluation of targets as a moral disengagement mechanism. Journal of Applied Psychology, 104(4), 495. https://doi.org/10.1037/apl0000359

Hussain, H.I., Sallehuddin, S., Shamsudin, M.F. \& Jabarullah, N.H. (2018) Debt Maturity Structure and Shari'ah Compliance: Evidence from Malaysia, European Research Studies Journal, 21 (1), 179 189.

lqbal, T., Huq, F., \& Bhutta, M. K. S. (2018). Agile manufacturing relationship building with TQM, JIT, and firm performance: An exploratory study in apparel export industry of Pakistan. International Journal of Production Economics, 203, 24-37. https://doi.org/10.1016/j.ijpe.2018.05.033

Jermsittiparsert, K., Siriattakul, P., \& Sangperm, N. (2019). Predictors of Environmental Performance: Mediating Role of Green Supply Chain Management Practices. International Journal of Supply Chain Management, 8(3), 877-888.

Jermsittiparsert, K., Siriattakul, P., \& Wattanapongphasuk, S. (2019). Determining the Environmental Performance of Indonesian SMEs Influence by Green Supply Chain Practices with Moderating Role of Green HR Practices. International Journal of Supply Chain Management, 8(3), 59-70. https://doi.org/10.1115/1.860281_ch4 
Jermsittiparsert, K. \& Sommanawat, K. (2019). TQM, Human Oriented Elements and Organizational Performance: A Business Excellence Model for Higher Education Institutes of Thailand. International Journal of Innovation, Creativity and Change, 5(2), 514-532.

Kang, C., Germann, F., \& Grewal, R. (2016). Washing away your sins? Corporate social responsibility, corporate social irresponsibility, and firm performance. Journal of Marketing, 80(2), 59-79. https://doi.org/10.1509/jm.15.0324

Kormishkina, L. A., Kormishkin, E. D., Gorin, V. A., Koloskov, D. A., Koroleva, L. P. 2019. Environmental investment: the most adequate neo-industrial response to the growth dilemma of the economy. Entrepreneurship and Sustainability Issues, 7(2), 929-948. http://doi.org/10.9770/jesi.2019.7.2(10)

Kozluk, T., \& Zipperer, V. (2015). Environmental policies and productivity growth. OECD Journal: Economic Studies, 2014(1), 155-185. https://doi.org/10.1787/eco_studies-2014-5jz2draml75j

Karle Pravin P, Dhawale Shashikant C. (2019). "Manilkara zapota (L.) Royen Fruit Peel: A Phytochemical and Pharmacological Review." Systematic Reviews in Pharmacy 10.1, 11-14. https://doi.org/10.5530/srp.2019.1.2

Lucangioli.S. "Acute Renal Failure: An Article Critique." International Journal of Pharmacy Research \& Technology 8.2 (2018), 51-52. https://doi.org/10.31838/ijprt/08.02.07

Li, D.-y., \& Liu, J. (2014). Dynamic capabilities, environmental dynamism, and competitive advantage: Evidence from China. Journal of Business Research, 67(1), 2793-2799. https://doi.org/10.1016/j.jbusres.2012.08.007

Liao, Z. (2016). Temporal cognition, environmental innovation, and the competitive advantage of enterprises. Journal of Cleaner Production, 135, 1045-1053. https://doi.org/10.1016/j.jclepro.2016.07.021

Lin, L.-H., \& Ho, Y.-L. (2016). Institutional pressures and environmental performance in the global automotive industry: the mediating role of organizational ambidexterity. Long Range Planning, 49(6), 764-775. https://doi.org/10.1016/j.Irp.2015.12.010

Luthra, S., Garg, D., \& Haleem, A. (2015). Critical success factors of green supply chain management for achieving sustainability in Indian automobile industry. Production Planning \& Control, 26(5), 339362. https://doi.org/10.1016/j.resourpol.2014.12.006

Nguyen, Q. A., \& Hens, L. (2015). Environmental performance of the cement industry in Vietnam: the influence of ISO 14001 certification. Journal of Cleaner Production, 96, 362-378. https://doi.org/10.1016/j.jclepro.2013.09.032

Pedersen, E. R. G., \& Andersen, K. R. (2015). Sustainability innovators and anchor draggers: a global expert study on sustainable fashion. Journal of Fashion Marketing and Management, 19(3), 315327. https://doi.org/10.1108/jfmm-08-2014-0059

Schaltegger, S., \& Wagner, M. (2017). Managing the business case for sustainability: The integration of social, environmental and economic performance: Routledge. https://doi.org/10.4324/9781351280525

Sekaran, U., \& Bougie, R. (2016). Research methods for business: A skill building approach: John Wiley \& Sons.

Shmueli, G., Ray, S., \& Chatla, S. B. (2016). The elephant in the room: Predictive performance of PLS models. Journal of Business Research, 69(10), 4552-4564. https://doi.org/10.1016/j.jbusres.2016.03.049

Shu, C., Zhou, K. Z., \& Gao, S. (2016). How green management influences product innovation in China: The role of institutional benefits. Journal of Business Ethics, 133(3), 471-485. https://doi.org/10.1007/s10551-014-2401-7 
Somjai, S. \& Jermsittiparsert, K. (2019). The Trade-off between Cost and Environmental Performance in the Presence of Sustainable Supply Chain. International Journal of Supply Chain Management, 8(4), 237-247.

Tzempelikos, N., \& Gounaris, S. (2017). A conceptual and empirical examination of key account management orientation and its implications-the role of trust The Customer is NOT Always Right? Marketing Orientationsin a Dynamic Business World (pp. 673-681): Springer. https://doi.org/10.1007/978-3-319-50008-9_185 